\title{
Stress and Burnout among Intensive Care Unit Healthcare Professionals in an Indian Tertiary Care Hospital
}

\author{
Lakshmikanthcharan Saravanabavan ${ }^{1}$, MN Sivakumar², ${ }^{2}$ ohamed Hisham ${ }^{3}$
}

\begin{abstract}
Intensive care unit (ICU) healthcare professionals work under a stressful environment which can lead to burnout syndrome. We conducted this study to evaluate the prevalence of stress and burnout syndrome among doctors and other healthcare professionals in ICU. We also evaluated the individual contributing factors for stress and burnout syndrome among these ICU healthcare workers. The cross-sectional survey was conducted among the healthcare professionals (doctors, nurses, clinical pharmacists, respiratory therapists and physiotherapists) in the ICUs of multispecialty hospital in south India. The survey was conducted using well-accepted tools which included job satisfaction scale, perceived stress scale and Maslach burnout inventory-human service survey. Overall, 204 healthcare professionals completed the survey. The prevalence of high burnout in our study was $80 \%$ which included $6 \%(n=12)$ of doctors and $69 \%(n=140)$ of nurses. Our study showed statistically significant correlation between level of job satisfaction and the level of burnout. There was a significant correlation between the level of stress and the emotional exhaustion and depersonalization domains of Maslach burnout inventory. Critical care societies and institutional committees should step forward to draft policies and benchmarks to curb the causes of stress, reduce burnout and to increase the job satisfaction.

Keywords: Burnout syndrome, Healthcare workers, Job stress

Indian Journal of Critical Care Medicine (2019): 10.5005/jp-journals-10071-23265
\end{abstract}

\section{INTRODUCTION}

Working in an intensive care unit (ICU) environment is known to be stressful. For all ICU healthcare workers more than the physical work, it is the psychological factor of dealing with the seriously ill patients which leads to huge mental stress. ${ }^{1,2}$ This includes discussion with patient family and relatives about the risk of death, to disclose deaths especially in an unexpected situation and to discuss end of life issues. ${ }^{3,4}$ This stress when persisting for quite some time can lead to burnout, which in turn can cause a decreased personal well-being, increased absenteeism, more mistakes and ultimately compromised patient care. ${ }^{5}$

Most studies from western countries have tried to correlate the level of stress and burnout but have not clearly elucidated the reasons for them. ${ }^{3,6}$ There were no major studies from developing countries. We conducted this study to evaluate the prevalence of stress and burnout syndrome among doctors and other healthcare professionals in ICU. We also evaluated the individual contributing factors for stress and burnout syndrome among these ICU healthcare workers.

\section{Materials and Methods}

\section{Study Design}

The cross-sectional survey was conducted among the healthcare professionals in the intensive care units (medical, surgical, trauma, neuro, cardiac and high dependency unit) of multispecialty, tertiary care hospital in south India. The healthcare workers who were enrolled in the survey included doctors, nurses, clinical pharmacists, respiratory therapists and physiotherapists. The Institutional Ethics Committee approval (EC/AP/396/07/2015) was obtained before commencing the survey.

\begin{abstract}
1,2Institute of Critical Care, Royal Medicine, Care Superspeciality Hospitals, Coimbatore, Tamil Nadu, India

${ }^{3}$ Department of Critical Care, Cleveland Clinics, Abu Dhabi, United Arab Emirates

Corresponding Author: Lakshmikanthcharan Saravanabavan, Institute of Critical Care, Royal Medicine, Care Superspeciality Hospitals, Coimbatore, Tamil Nadu, India, e-mail: drcharan01@gmail.com

How to cite this article: Lakshmikanthcharan S, Sivakumar MN, Hisham M. Stress and Burnout among Intensive Care Unit Healthcare Professionals in an Indian Tertiary Care Hospital. Indian J Crit Care Med 2019;23(10):462-466.
\end{abstract}

Source of support: Nil

Conflict of interest: None

\section{Study Population}

The self-assessment questionnaire was sent to 264 healthcare workers who have worked in the ICU within 6 months of the survey date. A total of 204 healthcare professionals completed the survey.

\section{Study Tools}

The anonymous, web-based and paper-based survey was carried out over 1 month in multiple ICUs. The first section of questionnaire included total of 30 questions on the demographic data (age, gender, marital status, qualification), personal information (number of children, smoking or alcohol consumption habits, hours of sleep), work-related information (years of experience, work hours, vacation days, salary, number of patients under their care, night shifts, ability to balance professional and personal works), working environmentrelated issues (relation with coworkers, respect from patients and their relatives, intention to leave the job) and health problems experienced in relation to work. We used 7-point Likert scale for some of the questions on the ability to manage work (where a

(0) The Author(s). 2019 Open Access This article is distributed under the terms of the Creative Commons Attribution 4.0 International License (https://creativecommons. org/licenses/by-nc/4.0/), which permits unrestricted use, distribution, and non-commercial reproduction in any medium, provided you give appropriate credit to the original author(s) and the source, provide a link to the Creative Commons license, and indicate if changes were made. The Creative Commons Public Domain Dedication waiver (http://creativecommons.org/publicdomain/zero/1.0/) applies to the data made available in this article, unless otherwise stated. 
Stress and Burnout among Intensive Care Unit Healthcare Professionals in an Indian Tertiary Care Hospital

Table 1: Subscale score cutoffs

\begin{tabular}{llll}
\hline Subscale score & Low burnout & $\begin{array}{l}\text { Moderate } \\
\text { burnout }\end{array}$ & High burnout \\
\hline Emotional exhaustion & $\leq 13$ & $14-26$ & $\geq 27$ \\
Depersonalization & $\leq 5$ & $6-9$ & $\geq 10$ \\
Personal & $\geq 40$ & $34-39$ & $\leq 33$ \\
accomplishment & & & \\
\hline
\end{tabular}

value of 1 scored badly and 7 scored superbly) and some of the questions on respect you get (where a value of 1 scored as not at all and 7 scored as extremely respected). These data elucidated the contributing factors associated with stress and burnout.

The remaining sections included the following well- accepted and validated psychometric tools:

- Warr, Cook and Wall job satisfaction scale - 10 questions version: It included the various aspects of the work type, responsibilities and the working conditions. Each question had a 7-point Likert score (where a value of 1 scored as extremely dissatisfied and 7 scored as extremely satisfied) to grade the level of satisfaction. It also included a question on the overall satisfaction score. ${ }^{7}$

- Cohen Perceived stress scale (PSS) - 10 questions version: It measures the perception of stress. The questions in the PSS ask about feelings and thoughts during the last month. In each case, respondents are asked how often they felt a certain way. Each question has a 5-point Likert score (where a value of 0 scored as never and 4 scored as very often). The combined score is used to grade the level of stress. ${ }^{8}$

- Maslach burnout inventory-human service survey (MBI-HSS): The MBI is a most commonly used tool to study burnout. It contains 22 questions that address three domains of burnout: emotional exhaustion (feeling unable to carry on), depersonalization (treating people as objects) and personal accomplishment (gaining satisfaction from the job). Each question had a 7-point Likert score (where a value of 1 scored as never and 6 scored as every day). A subscoring system is used to assess the level of burnout based on these three aspects. Overall high burnout is determined by a high score on the emotional exhaustion or depersonalization subscale, low score on the personal accomplishment subscale of the Maslach burnout inventory. Individual burnout scores from the three subscales are added and based on that score, the level of burnout is assessed (low $\leq 18$, moderate $19-35$, high $\geq 36$ ) as mentioned in Table 1. ${ }^{9,10}$

\section{Statistical Analysis}

Categorical variables were expressed as frequency (percentage); continuous variables were described as mean values with standard error. Descriptive analyses were done for the main outcome measures for overall and subscale burnout scores for all healthcare workers categorized with burnout as defined by the Maslach burnout inventory.

Univariate and bivariate analyses were done using Fisher's exact test for dichotomous outcomes and the Student t-test for normally distributed continuous outcomes. Multivariate analyses were done in the following manner to study the associations between individual healthcare workers and contributing risk factors. Correlative analyses were done using Pearson correlation for normally distributed variables. These analyses were done using each contributing risk factor against each of the main outcome measures. Statistical significance was defined as $p$ value less than 0.05 for a confidence interval of $95 \%$. All statistical analyses were performed with SPSS software (SPSS, version 23; IBM Corp., Armonk, NY).

\section{Results}

Overall, 204 healthcare professionals completed the survey which included 164 nurses, 21 doctors, 15 respiratory therapists, 2 physiotherapists and 2 clinical pharmacists. Nursing respondents from different critical care specialties included 57 from surgical and trauma, 44 from medical, 41 from high-dependency units, 11 from neuro and 11 from cardiac ICUs. Doctors and other healthcare workers had shift rotations within these units. Study participants with age less than 30 years were $83.33 \%(n=170)$ and $75.49 \%$ were females $(n=154)$. Educational qualification showed $62.25 \%(n=127)$ had a bachelor's degree as their primary qualification. Majority of survey respondents $56.37 \%(n=115)$ had less than one year of ICU experience and only $16.67 \%(n=34)$ of them had more than 3 years of experience. Eighty nine percent $(n=169)$ of the participants were single and the remaining married, none divorced or separated. Interestingly, smoking and alcohol consumption were very less with $1.96 \%(n=4)$ and only $28.92 \%(n=59)$ of them exercise regularly.

Analyzing the data on the working conditions showed, the mean with standard error (SE) work time was $8.74 \pm 0.09$ hours a day, $6.09 \pm 0.02$ days a week and average sleep time was $7.10 \pm 0.08$ (mean \pm SE) hours a day. There were almost $6.87 \pm 0.18$ (mean \pm $\mathrm{SE}$ ) night shifts per month and they take around $4.39 \pm 0.07$ (mean $\pm \mathrm{SE}$ ) days leave per month. Each nurse takes care of about $1.82 \pm$ 0.04 (mean \pm SE) patients per shift whereas a doctor is responsible for about $8.1 \pm 0.06$ (mean $\pm \mathrm{SE}$ ) patients.

Seventy nine percent $(n=161)$ participants were able to manage their ICU work efficiently, whereas $62.74 \%(n=128)$ were able to manage their work appropriately outside ICU. Only $12.74 \%(n=26)$ agreed that their work schedule gave them time for personal or family life whereas $36.76 \%(n=75)$ strongly disagreed to it. Majority were happy about the respect they got from their coworkers (74\%), respect from patients (83.82\%) and respect from patient's relatives (77.45\%). Eighty six percent of the doctors $(n=18)$ were satisfied with their annual pay check whereas only $48.08 \%(n=88)$ of the nurses and other healthcare workers were satisfied with their annual pay check. Interestingly, 38.2\% $(n=78)$ of the total participants revealed their plan of quitting their job from the current institution in the subsequent year.

Work-related health problems experienced by our study participants were $49.5 \%(n=101)$ headache, $57.3 \%(n=117)$ back pain, $41.6 \%(n=85)$ depression, $42.6 \%(n=87)$ lack of sleep, $29.9 \%$ $(n=61)$ memory loss and $31.3 \%(n=64)$ irritability.

Computing the data obtained from the Cohen's stress scale 1.96\% $(n=4)$ never had stress, 30.88\% $(n=63)$ almost never had stress, $54.9 \%(n=112)$ sometimes had stress, $12.25 \%(n=25)$ fairly often had stress and none had stress very often. Table 2 demonstrates that majority of the participants had high level of burnout in all the three domains of Maslach burnout inventory. Our study showed statistically significant correlation between level of job satisfaction and the level of burnout. As the level of job satisfaction decreases, there was a high level of burnout. There was a significant correlation between the level of stress and the emotional exhaustion and depersonalization domains of Maslach burnout inventory as illustrated in Table 3. 
Stress and Burnout among Intensive Care Unit Healthcare Professionals in an Indian Tertiary Care Hospital

Table 2: Correlation between job satisfaction and the three domains of Maslach burnout inventory

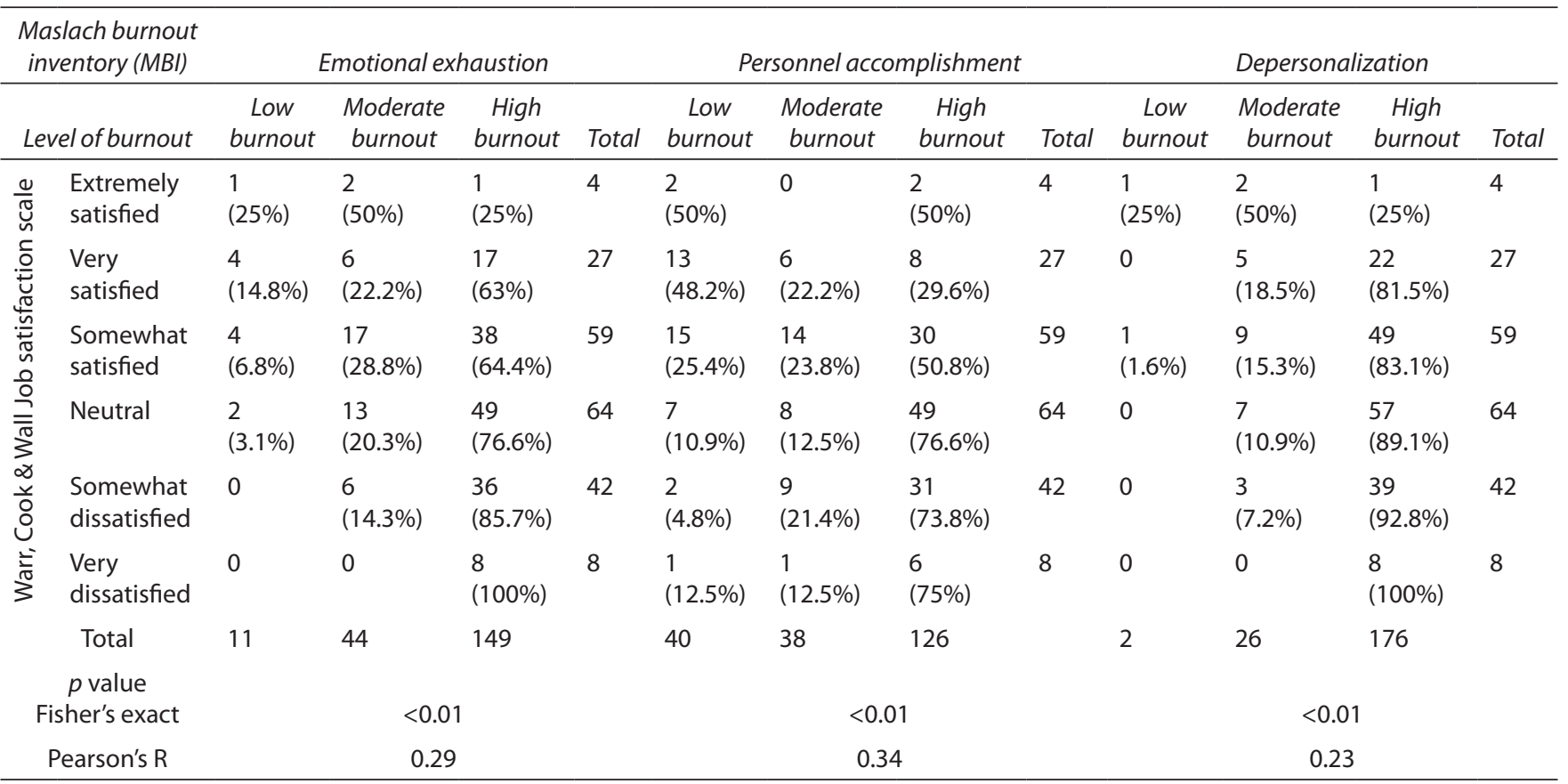

Table 3: Correlation between perceived stress scale and the three domains of Maslach burnout inventory

\begin{tabular}{|c|c|c|c|c|c|c|c|c|c|c|c|c|c|}
\hline \multirow{2}{*}{\multicolumn{2}{|c|}{$\begin{array}{c}\begin{array}{c}\text { Maslach burnout } \\
\text { inventory (MBI) }\end{array} \\
\text { Level of burnout }\end{array}$}} & \multicolumn{4}{|c|}{ Emotional exhaustion } & \multicolumn{4}{|c|}{ Personnel accomplishment } & \multicolumn{4}{|c|}{ Depersonalization } \\
\hline & & $\begin{array}{c}\text { Low } \\
\text { burnout }\end{array}$ & $\begin{array}{c}\text { Moderate } \\
\text { burnout }\end{array}$ & $\begin{array}{c}\text { High } \\
\text { burnout }\end{array}$ & Total & $\begin{array}{c}\text { Low } \\
\text { burnout }\end{array}$ & $\begin{array}{c}\text { Moderate } \\
\text { burnout }\end{array}$ & $\begin{array}{c}\text { High } \\
\text { burnout }\end{array}$ & Total & $\begin{array}{c}\text { Low } \\
\text { burnout }\end{array}$ & $\begin{array}{c}\text { Moderate } \\
\text { burnout }\end{array}$ & $\begin{array}{c}\text { High } \\
\text { burnout }\end{array}$ & Total \\
\hline \multirow{4}{*}{ 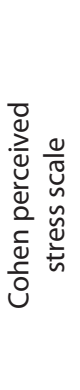 } & $\begin{array}{l}\text { Almost } \\
\text { never }\end{array}$ & $\begin{array}{l}3 \\
(33.3 \%)\end{array}$ & $\begin{array}{l}4 \\
(44.4 \%)\end{array}$ & $\begin{array}{l}2 \\
(22.3 \%)\end{array}$ & 9 & $\begin{array}{l}5 \\
(55.6 \%)\end{array}$ & $\begin{array}{l}1 \\
(11.1 \%)\end{array}$ & $\begin{array}{l}3 \\
(33.3 \%)\end{array}$ & 9 & $\begin{array}{l}1 \\
(11.2 \%)\end{array}$ & $\begin{array}{l}4 \\
(44.4 \%)\end{array}$ & $\begin{array}{l}4 \\
(44.4 \%)\end{array}$ & 9 \\
\hline & Sometimes & $\begin{array}{l}8 \\
(6.7 \%)\end{array}$ & $\begin{array}{l}33 \\
(27.7 \%)\end{array}$ & $\begin{array}{l}78 \\
(65.6 \%)\end{array}$ & 119 & $\begin{array}{l}18 \\
(15.1 \%)\end{array}$ & $\begin{array}{l}20 \\
(16.8 \%)\end{array}$ & $\begin{array}{l}81 \\
(68.1 \%)\end{array}$ & 119 & $\begin{array}{l}1 \\
(0.8 \%)\end{array}$ & $\begin{array}{l}19 \\
(16 \%)\end{array}$ & $\begin{array}{l}99 \\
(83.2 \%)\end{array}$ & 119 \\
\hline & Fairly often & 0 & $\begin{array}{l}6 \\
(9.5 \%)\end{array}$ & $\begin{array}{l}57 \\
(90.5 \%)\end{array}$ & 63 & $\begin{array}{l}11 \\
(17.5 \%)\end{array}$ & $\begin{array}{l}15 \\
(23.8 \%)\end{array}$ & $\begin{array}{l}37 \\
(58.7 \%)\end{array}$ & 63 & 0 & $\begin{array}{l}2 \\
(3.2 \%)\end{array}$ & $\begin{array}{l}61 \\
(96.8 \%)\end{array}$ & 63 \\
\hline & Very often & 0 & $\begin{array}{l}1 \\
(7.7 \%)\end{array}$ & $\begin{array}{l}12 \\
(92.3 \%)\end{array}$ & 13 & $\begin{array}{l}6 \\
(46.2 \%)\end{array}$ & $\begin{array}{l}2 \\
(15.4 \%)\end{array}$ & $\begin{array}{l}5 \\
(38.4 \%)\end{array}$ & 13 & 0 & $\begin{array}{l}1 \\
(7.7 \%)\end{array}$ & $\begin{array}{l}12 \\
(92.3 \%)\end{array}$ & 13 \\
\hline & Total & 11 & 44 & 149 & & 40 & 38 & 126 & & 2 & 26 & 176 & \\
\hline \multicolumn{14}{|c|}{$p$ value } \\
\hline & arson's R & \multicolumn{4}{|c|}{0.36} & \multicolumn{4}{|c|}{0.07} & \multicolumn{4}{|c|}{0.26} \\
\hline
\end{tabular}

\section{Discussion}

It is a well-known fact that ICU environment is not only stressful for the patient and relatives but also for the healthcare workers. There are many researches done in the western countries to substantiate this fact and they predominantly involved either the physicians or nurses individually. There is a scarcity of data from the Indian healthcare system where there is a huge difference in mentality of the people, cultural values and working conditions. Our study is unique in this aspect by including all the ICU healthcare professionals (physicians, nurses, clinical pharmacist, respiratory therapists and physiotherapists).

It is difficult to compare the studies done in the past with ours as there are different versions of Maslach burnout inventory being used to evaluate the level of burnout in each. We selected some prime studies done in France, Norway, Portugal and United Kingdom (UK) to compare some of the specific characters with our data. ${ }^{6,7,11,12}$ Our study included a large number of multidisciplinary participants comparable to the studies published from Norway and Portugal. ${ }^{7,12}$

In our study, majority of the participants were females with less than 30 years of age as most of the participants were nurses. These results were similar to all the studies which included only nurses. ${ }^{11,13,14}$ An Indian study by Amte and colleagues had a higher median age of more than 35 years as it included only doctors. ${ }^{15}$ Most of the study participants were qualified with a bachelor degree. These were contrasting with another Indian study among nurses by Saini and colleagues, where $48 \%$ participants only had a diploma degree. ${ }^{14}$ Most of the studies done on stress and burnout in critical 
care nurses had more participants with ICU experience of less than 5 years. ${ }^{11,13,14}$ Majority of the participants in our study had less than a year of experience in ICU. This can be explained by a major turnover among the nursing caregivers who relocate following their initial clinical experience after passing from our school of nursing.

Our study had lesser participants with habits of smoking and alcohol consumption when compared to UK study. ${ }^{6}$ These finding are expected as most of our study participants were female nursing caregivers and religious culture in our country are against these social habits especially for females.

Surveys from western European countries had less than 42 working hours per week and an Indian study had more than 60 working hours per week. ${ }^{11,12,15}$ Our survey had more than 50 working hours per week as there are 6 working days in a week and 8-9 hours shift per day. This implicates that working hours in India is higher and possibly contribute to more incidence of burnout among healthcare professionals.

In two multi-centered French studies, $50 \%$ of the intensivist and $60 \%$ of the ICU nurses with high level of burnout wished to quit their current jobs. ${ }^{11,16}$ In our study, $38 \%(n=78)$ participants irrespective of their level of burnout revealed their plan of leaving the ICU in subsequent year.

The most common work-related health problems in our study was back pain, headache, insomnia and depression. French study by Poncet and team, showed more incidence of sleep disruption and insomnia while, depression was least. ${ }^{11}$ Embriaco and colleagues evaluated the prevalence of depression among ICU doctors in a one-day national survey in 189 French ICUs. They concluded that symptoms of depression were present in $25 \%$ of the intensivist. 5,16

The prevalence of high burnout in our study was $80 \%$ which included $6 \%(n=12)$ of doctors and $69 \%(n=140)$ of nurses. All the three categories of Maslach burnout inventory had a high level of burnout in majority of the study participants. Studies from other countries showed the incidence of burnout among ICU healthcare professionals to be $31 \%$ in Portugal, up to $46.5 \%$ in France and $62 \%$ in Australia and New Zealand together. $5,12,17,18$

Our study revealed better job satisfaction among doctors than nurses. Our results showed that as the level of job satisfaction deceases the level of burnout increased. These findings were similar to the results from the Norway study conducted among ICU doctors and nurses. ${ }^{7}$

Some of the glaring reasons for the job dissatisfaction and stress that we could get from responses in our study were long working hours, low salary, frequent night shifts and managing high profile patients which were comparable to the previous studies. ${ }^{5,14,15}$ This may be due to the fact that ours is a developing country with limited resources and low economical power, there is a tendency to underpay the workers. ${ }^{19-21}$ Interestingly, sexual harassment and relationship disputes were less compared to the western studies, probably due to the cultural beliefs in this part of the world. 5,6

Based on the finding from our study, we in our institution have planned for a committee to help all healthcare workers to overcome stress and provide regular counseling sessions for them to avoid it to get to a stage of burnout. Some of the other important issues that we are planning to improve or to reduce the working hours, provide adequate rest after the night shift and to revise the salary. Maybe once all these are implemented, we can conduct another survey to find the impact of these interventions on the level of stress and burnout. Our results clearly show the impact of stress and job satisfaction on the level of burnout among our healthcare workers. This can also guide the critical care societies to institute policies and benchmarks to detect and sort the causes of burnout.

\section{Limitations}

Limitation of our study were it being a single center study which can be extended to a multi-centric study from different parts of the country with the help of the national critical care society. The other limitation was the relatively higher proportion of nurses compared to other healthcare professional and hence the difficulty to extrapolate the result on all of them as they are influenced predominantly by the nursing population. This problem again can be negated if we can do the study in future including multiple centers.

\section{Conclusion}

The level of stress and burnout was comparable to the western data. There is a significant relation between the stress levels and job satisfaction on the level of burnout among the critical care professionals. There should be a strong recommendation to curb the causes of stress and to increase the job satisfaction among the workers to prevent burnout. Critical care societies and institutional committees should step forward to draft policies and benchmarks to monitor stress and reduce the causes of burnout.

\section{Ethical Standard Statement}

Our study has been approved by the appropriate ethics committee and has therefore been performed in accordance with the ethical standards laid down in the 1964 Declaration of Helsinki and its later amendments. National laws have been observed too.

\section{Acknowledgments}

The authors would like to thank nursing caregivers RN Anitha Roselin and RN Sivashankari for their valuable contribution toward collecting the survey among nursing caregivers in all intensive care units.

\section{References}

1. Lo D, Wu F, Chan M, Chu R, Li D. A systematic review of burnout among doctors in China: a cultural perspective. Asia Pac Fam Med. 2018;17(3):1-13.

2. Li H, Cheng B, Zhu XP. Quantification of burnout in emergency nurses: A systematic review and meta-analysis. Int Emerg Nurs. 2018;39:46-54.

3. Nazir A, Smalbrugge M, Moser A, Karuza J, Crecelius C, Hertogh C, et al. The Prevalence of Burnout among Nursing Home Physicians: An International Perspective. JAMDA. 2018;19(1):86-88.

4. Gnerre P, Rivetti C, Rossi AP, Tesei L, Montemurro D, Nardi R. Work Stress and Burnout among Physicians and Nurses in Internal and Emergency Departments. ITJM. 2017;11(2):151-158.

5. Embriaco N, Papazian L, Kentish-Barnes N, Pochard F, Azoulay E. Burnout syndrome among critical care healthcare workers. Curr Opin Crit Care. 2007;13(5):482-488.

6. Coomber S, Todd C, Park G, Baxter P, Firth-Cozens J, Shore S. Stress in UK intensive care unit doctors. Br J Anaesth. 2002;89(6):873-881.

7. Myhren $\mathrm{H}$, Ekeberg $\mathrm{O}$, Stokland $\mathrm{O}$. Job satisfaction and burnout among intensive care unit nurses and physicians. Crit Care Res Pract. 2013;2013:786176.

8. Chaaya M, Osman H, Naassan G, Mahfoud Z. Validation of the Arabic version of the Cohen Perceived Stress Scale (PSS-10) among pregnant and postpartum women. BMC Psychiatry. 2010;10:111.

9. Shanafelt TD, Boone S, Tan L, Dyrbye LN, Sotile W, Satele D, et al. Burnout and satisfaction with work-life balance among US 
physicians relative to the general US population. Arch Intern Med. 2012;172(18):1377-1385.

10. Poghosyan L, Aiken LH, Sloane DM. Factor structure of the Maslach Burnout Inventory: An analysis of data from large scale crosssectional surveys of nurses from eight countries. Int J Nurs Stud. 2009;46(7):894-902.

11. Poncet MC, Toullic P, Papazian L, Kentish-Barnes N, Timsit JF, Pochard $\mathrm{F}$, et al. Burnout syndrome in critical care nursing staff. Am J Respir Crit Care Med. 2007;175(7):698-704.

12. Teixeira C, Ribeiro O, Fonseca AM, Carvalho AS. Burnout in intensive care units - A consideration of the possible prevalence and frequency of new risk factors: A descriptive correlational multicentre study. BMC Anesthesiol. 2013;13(1):38.

13. Zhang XC, Huang DS, Guan P. Job burnout among critical care nurses from 14 adult intensive care units in north eastern China: a crosssectional survey. BMJ Open. 2014;4(6):e004813.

14. Saini R, Sukhpal K, Karobi D. Assessment of stress and burnout among intensive care nurses at a tertiary care hospital. J Mental Health Hum Behav. 2011;16(1):43-48.

15. Amte R, Munta K, Gopal PB. Stress levels of critical care doctors in India: A national survey. Indian J Crit Care Med. 2015;19(5):257-264.
16. Embriaco N, Azoulay E, Barrau K, Kentish N, Pochard F, Loundou A, et al. High level of burnout in intensivists: prevalence and associated factors. Am J Respir Crit Care Med. 2007;175(7):686-692.

17. Mion G, Libert N, Journois D. Burnout-associated factors in anesthesia and intensive care medicine 2009 survey of the French Society of anesthesiology and intensive care. Ann Fr Anesth Reanim. 2013;32(3):175-188.

18. Shehabi Y, Dobb G, Jenkins I, Pascoe R, Edwards N, Butt W. Burnout syndrome among Australian intensivists: A survey. Crit Care Resusc. 2008;10(4):312-315.

19. Bawakid K, Abdulrashid O, Mandoura N, Shah HBU, Ibrahim A, Akkad NM, et al. Burnout of Physicians Working in Primary Health Care Centers under Ministry of Health Jeddah, Saudi Arabia. Cureus. 2017;9(11):e1877.

20. Chou L-P, Li C-Y, Hu SC. Job stress and burnout in hospital employees: comparisons of different medical professions in a regional hospital in Taiwan. BMJ Open. 2014;4(2):e004185.

21. Kawamuraa Y, Takayashikia A, Itoc M, Maenoa T, Seoa E, Maenoa T. Stress Factors Associated with Burnout Among Attending Physicians: A Cross-Sectional Study. J Clin Med Res. 2018;10(3):226-232. 